\title{
Pose Adjusting Simulation of Hydraulic Support Based on Mechanical-Electrical-Hydraulic Coordination
}

\author{
Zhaosheng MENG, Qingliang ZENG, Lirong WAN, Peng LIU
}

\begin{abstract}
The pose variations of the hydraulic support have significant influence on its performance. And the pose adjusting operations are required to be fast and precise, while they have typical mechanical-electric-hydraulic coordination characteristics which are challenging to simulate. In view of these problems, a method has been proposed in this work for accurately monitoring and controlling the pose of the hydraulic support, and using a suitable multi-software co-simulation model to simulate it. A mathematical model for pose monitoring and control was initially established.A teaching-learning-based optimization algorithm (TLBO) was then introduced to obtain the numerical solution of the nonlinear equations.Finally, a numerical model based on mechanical-electrical-hydraulic co-simulation was established. The model was tested and validated by using different pose signals. The results indicate that the pose controller developed in this paper can control the support pose well (iteration time less than $1 \mathrm{~s}$ and cumulative error less than $1.5 \mathrm{~mm}$ ). Moreover, the multi-software co-simulation approach was effective for describing the complex system. The co-simulation platform proposed in this study can benefit the virtual monitoring technology for hydraulic supports. The research provides theoretical basis and technical guidance for the automation and unmanned control of underground mining.
\end{abstract}

Keywords: hydraulic support; numerical simulation; pose monitoring and controlling; TLBO

\section{INTRODUCTION}

Longwall mining has gradually become the most predominant mining method worldwide for the underground extraction of coal seams since its introduction in America in the 1950s [1, 2]. The basic equipment of longwall method includes a shearer to cut the coal seam, an armoured face conveyor (AFC) to transport the coal, and a series of hydraulic supports to prevent excessive roof-tofloor convergence and to provide a safe environment for all the above activities [3,4]. To this end, hydraulic supports must be advanced with minimum delay and rise quickly to reduce the exposure time of the roof $[5,6]$. However, the roof within mines is rarely parallel to the floor as the shearer can cut the roof unevenly (the roof is inclined). If the support leg rises freely without being controlled, it will take the operators a long time to adjust the support to the inclined roof. Then, the roof control becomes complex. During the supporting process, the support is commonly used in a tilting pose due to the absolute subsidence of the roof [7]. Once the sloping angle of the canopy exceeds the maximum allowable value, the support may lose its stability and then lead to support failure problems. At this stage, the behaviour of the support requires manual control to manage the roof more effectively.

Since hydraulic support plays a very important role in underground exploitation, many studies have been performed to ensure its proper operation. For example, to determine the appropriate capacity of a support for maintaining the roof in longwalls, a numerical modelling method has been widely adopted [8-12]. The data from monitoring systems or shield control systems were utilized in the shield performance evaluation at longwall faces. Based on the shield leg data, various shield-roof strata interaction models have been proposed [5, 6, 13]. In contrast, the support is typical passive supporting equipment whose support capacity is not only determined by the external load but also affected by its pose changes $[14,15]$. Therefore, the research on the pose monitoring and controlling technology of the hydraulic support is not only helpful to improve the intelligent level of the working face, but also helps to realize the stepless evaluation of the supporting performance of the support.

To determine the supporting status of the support in real time, it is necessary to first monitor its real-time pose. Thus, studies on the pose monitoring and controlling of the support aim to solve the following two problems: 1) adjusting the canopy to the inclined roof automatically during the rising period to achieve a rapid initial setting, 2) monitoring the status of the support and preventing it from being damaged. However, until now, very few studies related to the pose adjustment problem of the support have been reported [15]. Studying the pose adjustment of support is of great significance for intelligent support of the working face. In addition, the hydraulic support is a complex system that includes the hydraulic drive unit, mechanical structure unit, and electrical control unit. Therefore, the pose adjusting operations of the support have typical mechanical-electric-hydraulic coordination characteristics. The coupling simulation method using multiple software programs has been widely applied to solve multi-domain coupling problems, e.g. continuous miners [16], robots [17], variable displacement pumps [18], and vehicles $[19,20]$. However, only few literature reports refer to three or more domain co-simulation problems [21].

The above discussion shows that the existing work on pose adjustment of the hydraulic support is incomplete, as scholars have so far focused only on the pose monitoring process. Thus, the pose control process is omitted. Moreover, the widely used genetic algorithms and dichotomous methods cannot meet the high speed and high precision requirements of the pose calculation of the hydraulic support. For simulation of pose adjustment of the support, a multi-domain co-simulation method is efficient and helpful to achieve a pre-verification of pose control scheme of the support [21]. Therefore, a mathematical model for pose monitoring and control of the support is established in this article. The teaching-learning-based optimization algorithm (TLBO) is introduced to achieve fast and accurate convergence towards the true pose value. The dynamics simulations software ADAMS, AMEsim, and Simulink are used to establish the mechanical- 
hydraulic-electrical three-domain co-simulation platform. By using a ZY21000/38/82 type shield support as an example, the pose adjusting behaviour is thoroughly investigated.

The rest of the study is organized as follows. Section 2 analyses the mechanism of the support and establishes the mathematical model for the pose monitoring and control of the support. Section 3 introduces the TLBO algorithm to solve the nonlinear pose monitoring model. Section 4 constructs the mechanical-electrical-hydraulic cosimulation model of the shield support and presents the pose adjusting results. Section 5 summarizes the conclusions.

\section{METHODOLOGY}

\subsection{Mechanism of Hydraulic Support}

Fig. 1 shows a 2-leg shield support, which consists of the base, the front bar, the rear bar, the goaf shield, the canopy, the equilibrium jack and the leg. Among these, the leg and the equilibrium jack are the driving parts, and the rest are the driven parts. As can be seen, the support is a seven-bar system that consists of three closed vector loops: ABCD, EFG, and JABEI. The degree-of-freedom (DOF) of the system is calculated as follows [22]:

$$
M=(6-\lambda)(n-g-1)+\sum_{i=1}^{g} f_{i}-v-q
$$

where $M$ is DOF of the system, $\lambda$ is general constraint of the system, $n$ is number of bodies in the system, $g$ is number of joints, $f_{i}$ is number of DOFs of the $i$-th joint, $v$ is redundant constraints, and $q$ is local DOF of the system. For the presented system, $\lambda=3, n=10, g=12, v=0, q=1$ and $f_{i}=12$. Then:

$M=(6-3)(10-12-1)+12-0-1=2$

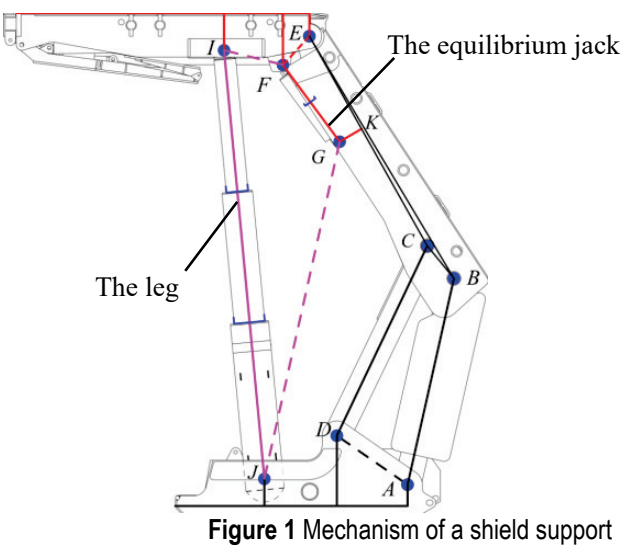

\subsection{Pose Monitoring Model of the Support}

It is advisable to first develop an appropriately simplified mechanical model to establish the pose monitoring mathematical model of the support [23]. The model built in this paper is based on the following assumptions: 1) the action deviation of the support caused by the assembly error is ignored; 2) the support is regarded as a rigid body. Fig. 2 shows the sketch of the support structure.
Since the mechanism has 2 DOFs, the pose of the support can be determined by monitoring two control variables. The two variables selected in this study are the lengths of the leg and the equilibrium jack (can be obtained using pull on the rope displacement sensors). The loopclosure condition of the vectors JABEI and EFG can be written as:

$$
\begin{aligned}
& \boldsymbol{l}_{\boldsymbol{z}}=\boldsymbol{h}_{3}+\boldsymbol{l}_{9}+\boldsymbol{h}_{1}+\boldsymbol{l}_{1}+\boldsymbol{l}_{5}+\boldsymbol{h}_{4}+\boldsymbol{l}_{8}+\boldsymbol{h}_{6} \\
& \boldsymbol{l}_{\boldsymbol{q}}=\boldsymbol{l}_{6}+\boldsymbol{l}_{7}
\end{aligned}
$$

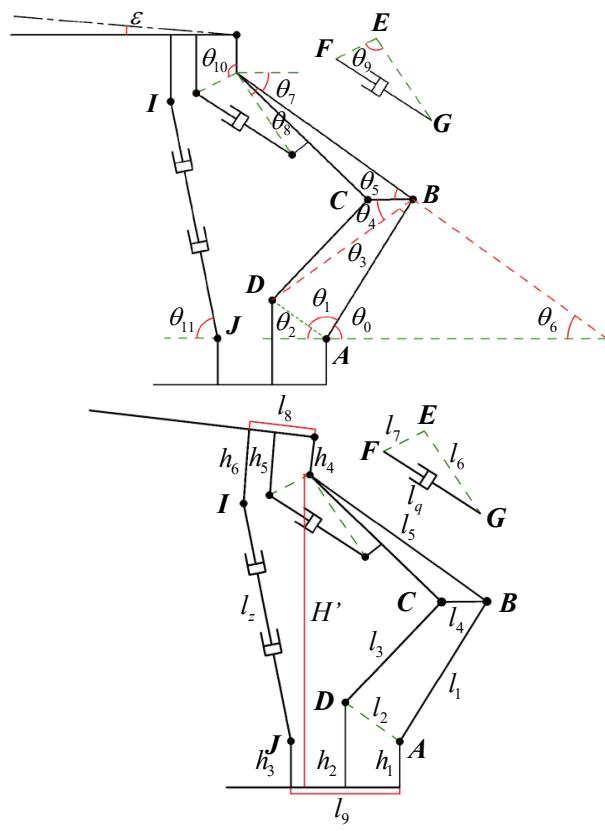

Figure 2 Skeleton model of the support

The vector Eq. (3) can be rewritten as a system of two scalar equations with four unknowns, $l_{z x}, l_{z y}, \theta_{0}$, and $\varepsilon$ :

$l_{z x}=l_{9}+l_{1} \cos \theta_{0}-l_{5} \cos \theta_{7}+h_{4} \sin \varepsilon-l_{8} \cos \varepsilon+h_{6} \sin \varepsilon$

(5)

$l_{z y}=h_{1}+l_{1} \sin \theta_{0}+l_{5} \sin \theta_{7}+h_{4} \cos \varepsilon+l_{8} \sin \varepsilon-h_{3}-h_{6} \cos \varepsilon$

(6)

The compatibility equations are introduced:

$$
\begin{aligned}
& l_{z}=\sqrt{l_{z x}^{2}+l_{z y}^{2}} \\
& \varepsilon=\theta_{7}+\theta_{8}+\theta_{9}+\theta_{10}-\frac{3 \pi}{2}
\end{aligned}
$$

Where:

$$
\begin{aligned}
& \theta_{6}=\theta_{7}=\theta_{3}+\theta_{4}+\theta_{5}-\theta_{0} \\
& \theta_{3}=\cos ^{-1}\left\{\frac{\left[2 l_{1}^{2}+2 l_{1} l_{2} \cos \left(\theta_{0}+\theta_{2}\right)\right]}{\left(2 l_{1} \sqrt{\left(l_{1}^{2}+l_{2}^{2}-2 l_{1} l_{2} \cos \theta_{1}\right)}\right)}\right\} \\
& \theta_{4}=\cos ^{-1}\left\{\frac{\left[l_{1}^{2}+l_{2}^{2}-l_{3}^{2}+l_{4}^{2}+2 l_{1} l_{2} \cos \left(\theta_{0}+\theta_{2}\right)\right]}{\left(2 l_{4} \sqrt{\left(l_{1}^{2}+l_{2}^{2}-2 l_{1} l_{2} \cos \theta_{1}\right)}\right)}\right\}
\end{aligned}
$$


The vector Eq. (4) can be rewritten as

$\theta_{9}=\frac{\left(l_{6}^{2}+l_{7}^{2}-l_{q}^{2}\right)}{2 l_{6} l_{7}}$

By substituting Eqs. (5)-(6) and (9)-(12) into Eqs. (7)(8), the pose monitoring equations of the support with two unknowns $\left(\theta_{0}\right.$ and $\left.\varepsilon\right)$ are obtained. Therefore, the equations are solvable in theory. However, the equations are quadratic with trigonometric functions (transcendental equations). Numerical solutions of the equations are provided in Section 3.

\subsection{Pose Control Model of the Support}

In Section 2.2, $\theta_{0}$ and $\varepsilon$ are dependent variables whereas $l_{z}$ and $l_{q}$ are independent variables. In contrast, in the pose controlling process, the target pose of the support are known ( $\theta_{0}$ and $\varepsilon$ are independent variables, and can be obtained using acceleration sensors), whereas the lengths of the leg and equilibrium jack are unknown $\left(l_{z}\right.$ and $l_{q}$ are dependent variables). By substituting $\theta_{0}$ and $\varepsilon$ into Eqs. (10)-(12), $\theta_{3}, \theta_{4}, \theta_{7}$, and $\theta_{9}$ are all obtained.

By combining Eqs. (8)-(12), $l_{q}$ is obtained:

$l_{q}=\sqrt{l_{6}^{2}+l_{7}^{2}-2 l_{6} l_{7} \cos \varepsilon}$

By substituting $\theta_{3}, \theta_{4}, \theta_{7}$, and $\theta_{9}$ into Eqs. (5)-(7), $l_{z}$ is obtained:

$l_{z}=\sqrt{l_{z x}^{2}+l_{z y}^{2}}$

Therefore, an analytical solution is obtained for the pose control model of the support.

\section{TLBO ALGORITHM FOR THE POSE MONITORING MODEL}

Many intelligent algorithms such as the Genetic Algorithm, Cuckoo Search, TLBO, and Differential Evolution have been used to solve nonlinear problems, e.g. optimal design of four-bar mechanisms [24, 25], path generation problems of planar mechanisms [26-28], and kinematics analysis of robots [29-31]. First introduced in 2010, the TLBO is a meta-heuristic teaching-learningbased optimization algorithm. Compared to the other algorithms, it converges fast, is highly consistent and requires less user-supplied parameters [32-34], which meet the high precision and high speed requirements for hydraulic support pose calculation. Therefore, the TLBO algorithm is used to obtain the numerical solutions of the pose monitoring equations in this study.

\subsection{TLBO Algorithm}

In the TLBO algorithm, the individual with the best performance is regarded as the teacher, while the others are treated as students. Correspondingly, there are two main phases in TLBO to perform the search, i.e. the Teacher Phase and the Learner phase.
(1) Teacher Phase: In this phase, learners obtain knowledge from the teacher and the teacher tries to enhance the mean result of the learners. Assume $m$ is total number of learners (i.e. population size), $n$ is number of subjects (i.e. design variables), $A$ is mean result of the learners in a subject, $T$ is level of the teacher (best level), and $F$ is learning level of the learner. Then, the teaching phase can be expressed as:

$F_{i, j}^{\text {new }}=F_{i, j}^{\text {old }}+r_{j}\left(T_{j}-T_{F} A_{j}\right)$

Where $i=1,2, \ldots, m, j=1,2, \ldots, n$. The term $r_{j}$ is a uniform random number varying from 0 to 1 , and $T_{F}$ is a teaching factor, randomly selected as 1 or 2 .

(2) Learner Phase: In this phase, learners increase their knowledge by interacting among themselves. A learner whose knowledge is $F_{i, j}$ randomly selects another student with knowledge of $F_{k, j}$ for interaction; the learner with the higher knowledge teaches the other one. Thus, the learning phase is expressed as:

If $F_{i, j}^{\text {old }}<T_{F} F_{k, j}^{\text {old }}$

$F_{i, j}^{\text {new }}=F_{i, j}^{\text {old }}+r_{j}\left(F_{k, j}^{\text {old }}-T_{F} F_{i, j}^{\text {old }}\right)$ where, $i \neq k$

Else

$F_{i, j}^{\text {new }}=F_{i, j}^{\text {old }}+r_{j}\left(F_{k, j}^{\text {old }}-T_{F} F_{k, j}^{\text {old }}\right)$ where, $i \neq k$

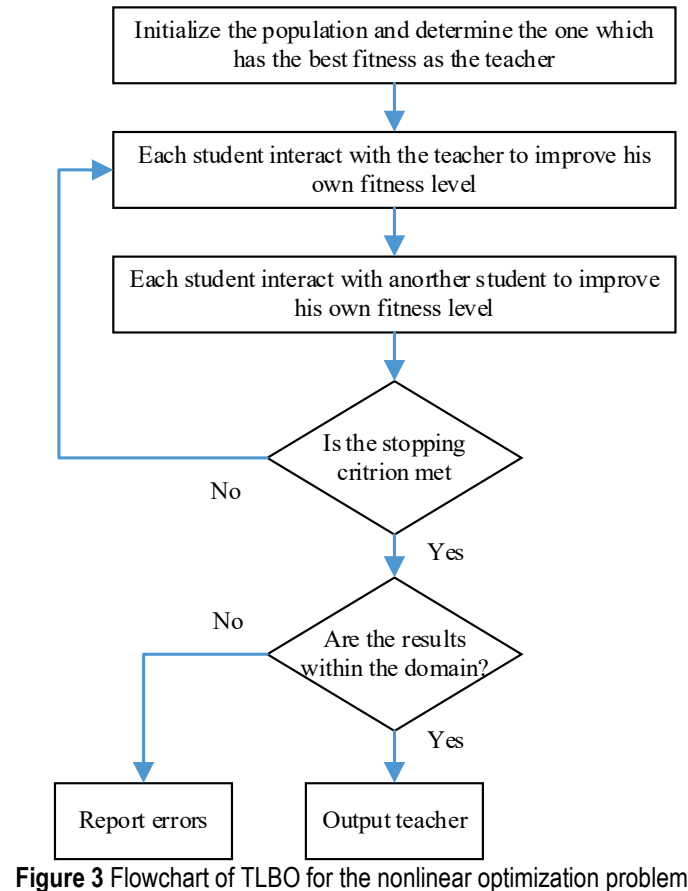

\subsection{Implementation of the TLBO}

The flowchart of the TLBO for the problem in this study is shown in Fig. 3. It mainly consists of four steps:

(1) Initialization: Randomly generate the population individuals (this study considered 50 individuals). Define the individual with the best fitness level as the teacher.

(2) Teacher Phase: Calculate $A_{j}, r_{j}$, and $T_{F}$ and repeat Equation (16) for each student.

(3) Learner Phase: For any learner, randomly select another learner for interaction. 
(4) If the termination criteria are met, the optimal solution is obtained. Otherwise, repeat the Step 2 until the optimal solution is obtained.

\subsection{Numerical Results}

In this study, the large mining height support ZY21000/38/82 type is taken as an example. Its variations in pose parameters during the horizontal rising process are solved to verify the effectiveness of the pose monitoring model and the TLBO algorithm.

The pose monitoring model presented in Section 2.2 is transformed into the nonlinear optimization problem as:

$$
\begin{aligned}
& f_{1}\left(\theta_{0}, \varepsilon\right)=\min \left|l_{z}-\sqrt{l_{z x}^{2}+l_{z y}^{2}}\right|\left(36.68 \leq \theta_{0} \leq 80\right) \\
& f_{2}\left(\theta_{0}, \varepsilon\right)=\min \mid \varepsilon-\left(\theta_{7}+\theta_{8}+\theta_{9}+\theta_{10}-\frac{3 \pi}{2} \mid\right. \\
& (-20 \leq \varepsilon \leq 20)
\end{aligned}
$$

The fitness function is defined as in Eq. (20):

$$
F_{f}=\frac{\left(\Delta_{1}+\Delta_{2} \times 100\right)}{\Sigma \Delta}
$$

Where $\Delta_{1}=\left|l_{z}-\sqrt{l_{z x}^{2}+l_{z y}^{2}}\right| \quad, \quad \Delta_{2}=\mid \varepsilon-\left(\theta_{7}+\theta_{8}+\theta_{9}+\theta_{10}\right.$ $-3 \pi / 2) \mid$, and $\Sigma \Delta=\left|l_{z}\right|+\left|\theta_{7}+\theta_{8}+\theta_{9}+\theta_{10}-3 \pi / 2\right| ; 100$ is gain coefficient. The introduction of gain coefficient can significantly improve the accuracy of numerical solutions, because the effect of $\Delta_{1}$ on $F_{f}$ is much greater than that of $\Delta_{2}$

Structural parameters of the support are substituted into Eqs. (18)-(20), and the numerical solutions for $\theta_{0}\left(\theta_{0}^{*}\right)$ and $\varepsilon\left(\varepsilon_{0}^{*}\right)$ during the horizontal rising process of the support are obtained as shown in Fig. 4. As can be seen, the calculation errors of both $\theta_{0}$ and $\varepsilon$ are less than 0.05 degree. Fig. 5 shows the value of the objective function corresponding to the number of iterations when the operating height of the support is $5903 \mathrm{~mm}$. The results show that the algorithm has a good convergence, and can achieve fast and accurate convergence to the expected values $\theta_{0}$ and $\varepsilon$ (in 150 iterations and $0.9 \mathrm{~s}$ ).

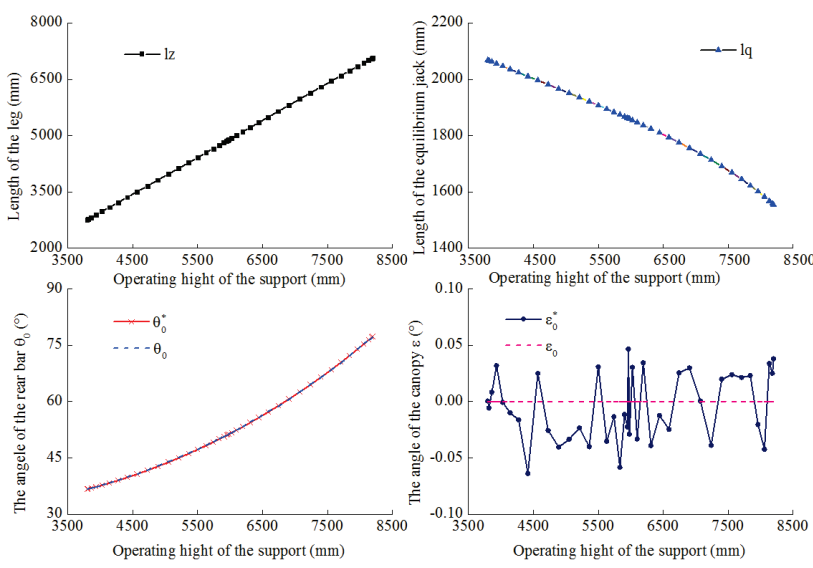

Figure 4 Numerical solutions for the pose monitoring equations

\section{REALIZATION OF POSE ADJUSTING PROCESS BASED ON MECHANICAL-HYDRAULIC-ELECTRICAL CO-SIMULATION}

In Section 3, the mathematical models for pose monitoring and control of the support were constructed, and the approximate numerical solutions were obtained for the pose monitoring equations. On this basis, this section aims to study the pose control behaviour of hydraulic support using a co-simulation method.

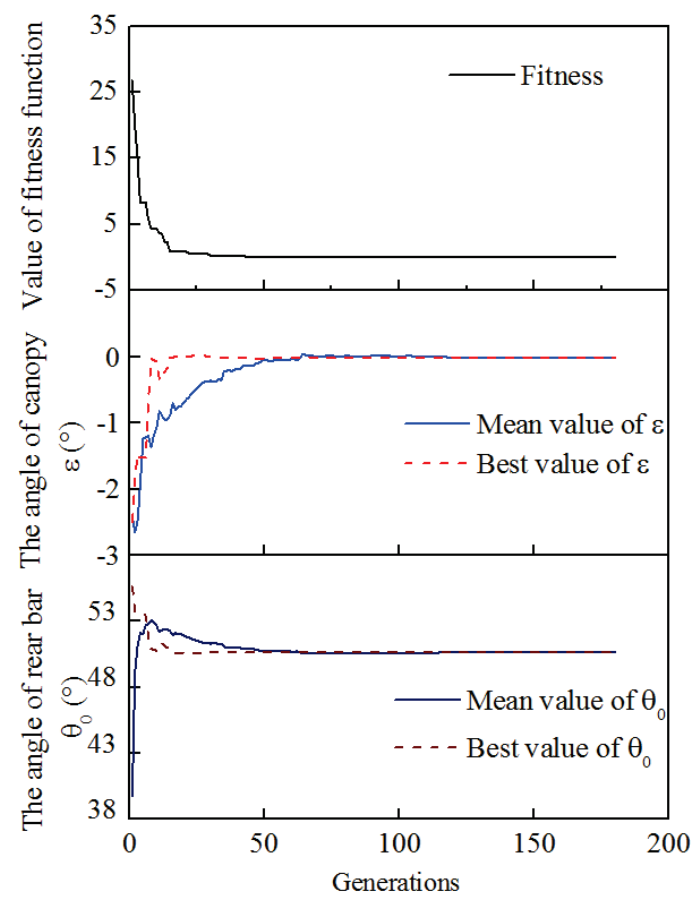

Figure 5 Value of the objective function corresponding to the number of generations

\subsection{Multi-Body Dynamic Model of the Support}

This study focuses on the pose adjusting behaviour of the support. Therefore, minor deformations can be ignored, and the support is considered as rigid. The numerical model of the support is prepared using PRO/E software, and the multi-body dynamic model shown in Fig. 6 is constructed with ADAMS software [35]. The support is initially set at the lowest operating height, the base is mounted on the ground with a fixed joint, the piston slides through the translational joint into the barrel (for the leg and the equilibrium jack)

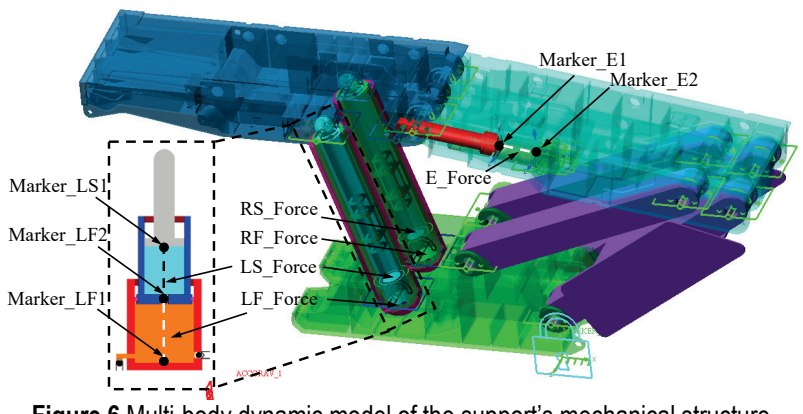

Figure 6 Multi-body dynamic model of the support's mechanical structure

In order to realize the collaborative interactive computation, MARKER points are built in the center of the 
piston and the bottom of each cylinder respectively, as shown in Fig. 6. By using the Controls PlantExport tool of the ADAMS software, the driving forces of the cylinders (LS_Force, LF_Force, RS_Force, RF_Force and E_Force) are defined as input variables, and the corresponding displacement (LS_Position, LF_Position, RS_Position, RF_Position and E_Position) and velocity (LS_Velocity, LF_Velocity, RS_Velocity, RF_Velocity and E_Velocity) are defined as output variables, respectively. The analysis, animation and simulation type/mode are set as non_linear, interactive and discrete, respectively. The mechanical module of the hydraulic support exported to the Simulink is shown in Fig. 7.

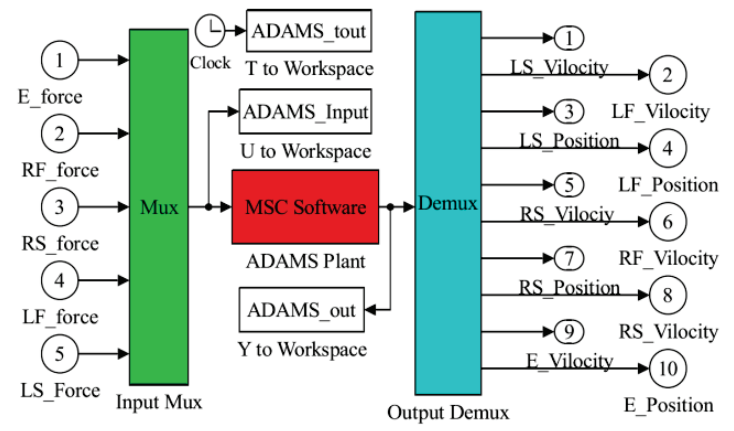

Figure 7 Mechanical module variables of the hydraulic support in Simulink

\subsection{Hydraulic Model of Support's Hydraulic System}

Fig. 8 describes the hydraulic system of the support. The hydraulic pilot check valve FDY1000/50 and the bidirectional hydraulic lock FDS125/50 lock the leg circuit and the equilibrium jack circuit, respectively. The large relief valves FAD1000/50 and FAZ1000/50 protect the leg and the equilibrium jack from overload, respectively. L_CS, R_CS, and E_CS are control signals of the solenoid directional valves of the left leg, right leg and equilibrium jack, respectively. The control signals are obtained from Section 4.3.

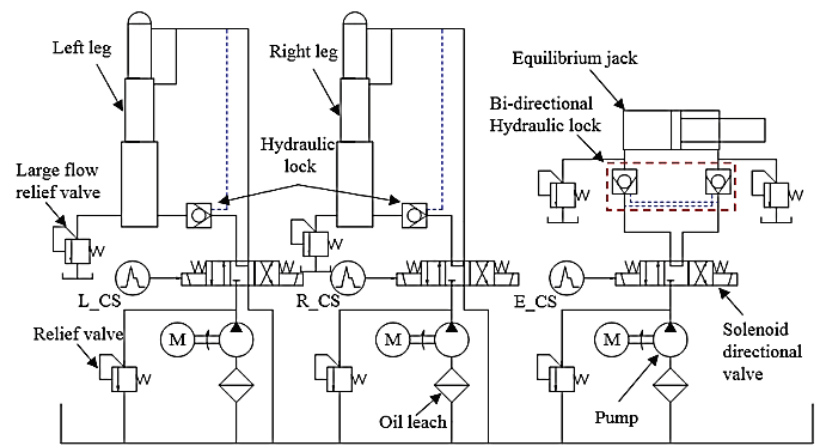

Figure 8 Schematic of support's hydraulic system.

AMESim software is a simulation platform to establish and analyse complex systems in 1-D form. Fig. 9 depicts the simplified support's hydraulic system model. The large flow relief valve (nominal flowrate is $1000 \mathrm{~L} / \mathrm{min}$ and the opening pressure is $50 \mathrm{MPa}$ ) and the hydraulic pilot check valve (nominal flowrate is $800 \mathrm{~L} / \mathrm{min}$ and the pressure drop is $1.5 \mathrm{MPa}$ ) are built using the hydraulic component design (HCD) library in AMESim and then packaged into super components. The nominal flowrate and pressure drop of the leg solenoid directional valve and equilibrium jack solenoid directional valve are $1500 \mathrm{l} / \mathrm{min}$ and $100 \mathrm{l} / \mathrm{min}$, and $0.3 \mathrm{MPa}$ and $0.1 \mathrm{MPa}$. The parameters of the leg and the equilibrium jack are set as Tab. 1. The external load represents the gravity load of the canopy, and the transfer function of the leg force represents the influence of leg on equilibrium jack. Both the modules are automatically calculated in ADAMS.

All the above model data are transformed to the Simulink in the Mexw64 format using Simucosim tool, and the communication interval is $0.0005 \mathrm{~s}$ (half the time of that in ADAMS). The hydraulic module of the hydraulic support exported to the Simulink is shown in Fig. 10.

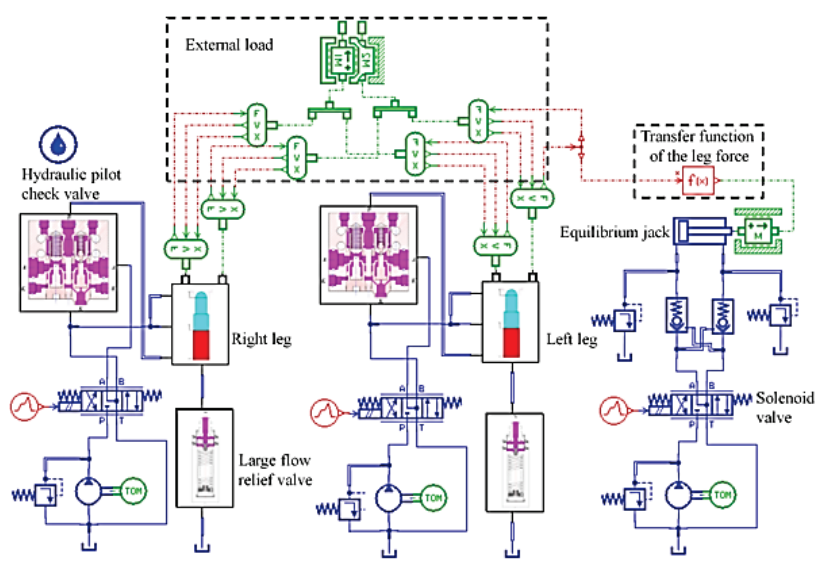

Figure 9 AMESim model of the support system

Table 1 Parameters of the leg and the equilibrium jack
\begin{tabular}{|c|c|c|c|}
\hline Item & $\begin{array}{c}\text { Piston Diameter } \\
(\mathrm{mm})\end{array}$ & $\begin{array}{c}\text { Rod diameter } \\
(\mathrm{mm})\end{array}$ & $\begin{array}{c}\text { Stroke } \\
(\mathrm{mm})\end{array}$ \\
\hline $\begin{array}{c}\text { The first stage of } \\
\text { the leg }\end{array}$ & 530 & 500 & 2197 \\
\hline $\begin{array}{c}\text { The second stage } \\
\text { of the leg }\end{array}$ & 380 & 355 & 2133 \\
\hline Equilibrium jack & 320 & 230 & 560 \\
\hline
\end{tabular}

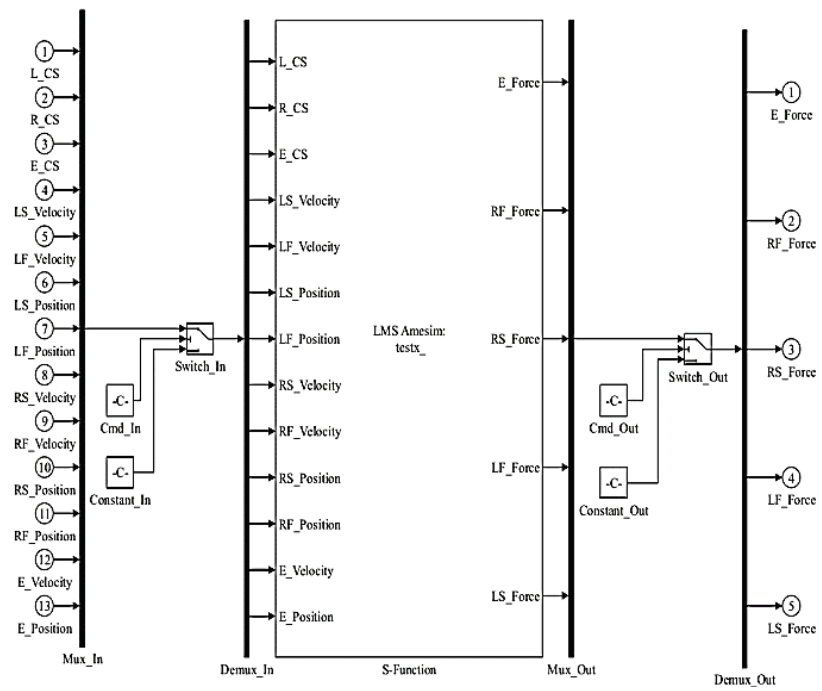

Figure 10 Hydraulic module variables of the hydraulic support in Simulink

\subsection{Electrical Model of Support Pose Control System}

In this study, a pose controller is developed by using analytical equations in Section 2.3 and implemented as a Matlab function in the Simulink environment (see Fig. 11). The user inputs the target pose of the support $\left(\theta_{0}\right.$ and $\left.\varepsilon\right)$, and the controller will automatically output the length of the leg $\left(l_{z}\right)$ and equilibrium jack $\left(l_{q}\right)$. 


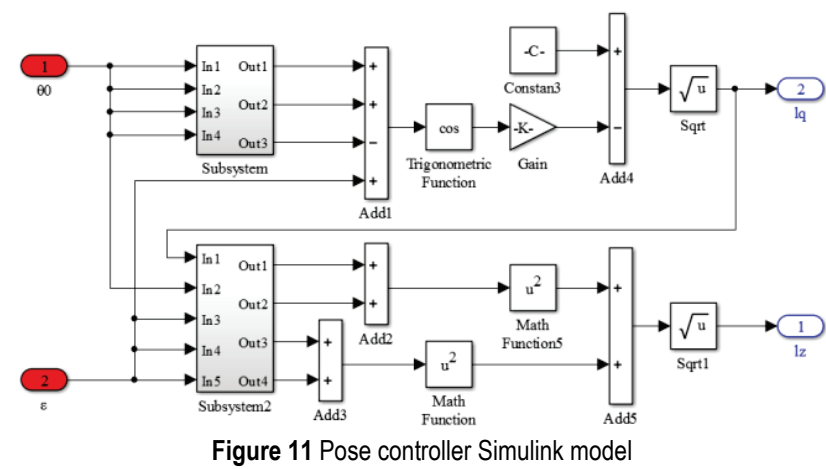

The PID control method was used as shown in Fig. 12 to ensure the control accuracy. By comparing the current length and target length of the left leg, right leg and equilibrium jack, the PID controller outputs control signals L CS, R CS and E CS to control the opening and closing of the solenoid valves of the left leg, right leg and equilibrium jack. Thus the lengths of the corresponding hydraulic cylinders are adjusted, respectively. The pose controller is packaged into a subsystem. An accuracy tolerance module is set ( $\pm 2 \mathrm{~mm})$ to make the output control signal of PID controller achieve a rapid convergence. Since control current of the solenoid valve is $\pm 40 \mathrm{~mA}$, a saturation module is set to restrict the value of the output signal.

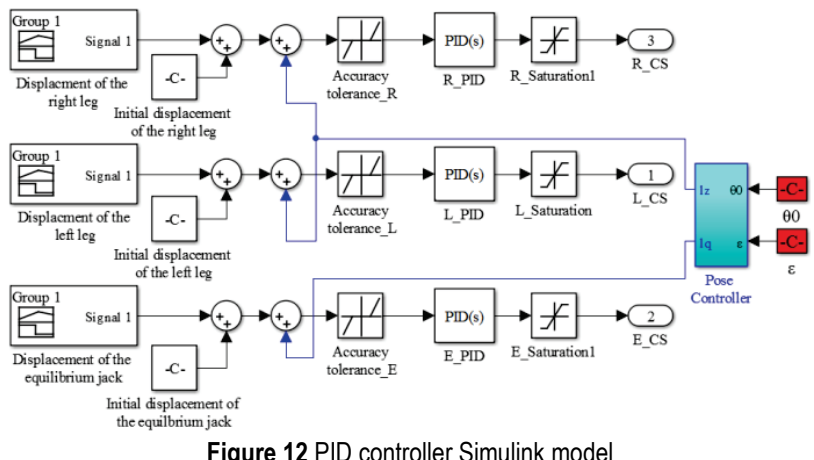

\subsection{Mechanical-Hydraulic-Electrical Co-Simulation Model of the Support}

The co-simulation model was built using software interfaces as shown in Fig. 13. Considering the units coordination among software, the unit conversion gain is set in AMEsim: the gain of speed and displacement is $1 / 1000$, and the gain of force is 1 . The initial displacement for the legs and quilibrium jack is $0 \mathrm{~mm}$ and $518 \mathrm{~mm}$, respectively.

The simulation of the mechanical system module was run using ADAMS/Solver $(\mathrm{C}++)$. AMESim read the mechanical calculation results through the SimuCosim interface. The standard integrator was used, and the calculating tolerance was $1 \mathrm{e}-05$. Both the modules were compiled into S-Functions in Matlab. The data interaction time interval was $0.001 \mathrm{~s}$, and the command ode 45 with viriable steps was used to solve the initial value problem with Matlab.

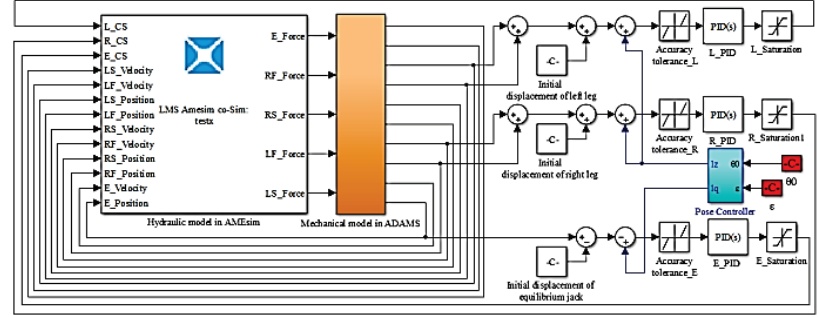

(a)

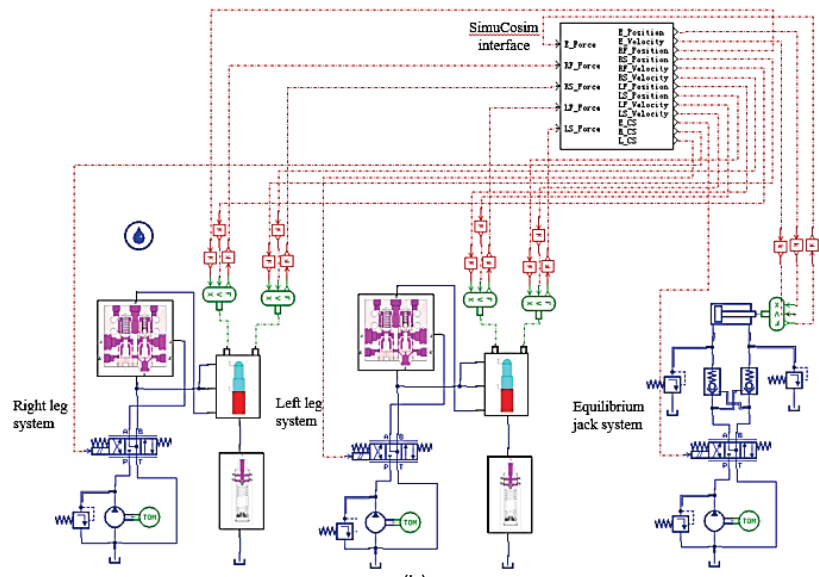

(b)

Figure 13 (a) Numerical model in Simulink, (b) Numerical model in AMESim

\subsection{Numerical Results}

The main purpose of the numerical simulation is to verify the feasibility of the proposed pose control method. The flow rates of the pump for the leg system and the equilibrium jack were set to $1500 \mathrm{l} / \mathrm{min}$ and $40 \mathrm{l} / \mathrm{min}$, respectively, to accelerate the simulation. The input pose parameters of the support were set as shown in Tab. 2, where $l_{z}$ and $l_{q}$ are the calculated lengths of the leg and the equilibrium jack.

Table 2 Pose parameters of the support

\begin{tabular}{|c|c|c|c|c|}
\hline Time $(\mathrm{s})$ & $\theta_{0}\left(^{\circ}\right)$ & $\varepsilon\left(^{\circ}\right)$ & $l_{z}(\mathrm{~mm})$ & $l_{q}(\mathrm{~mm})$ \\
\hline $0-12$ & 44.67 & -5.05 & 1200 & -180 \\
\hline $12-20$ & 43.10 & -4.28 & 1000 & -150 \\
\hline
\end{tabular}

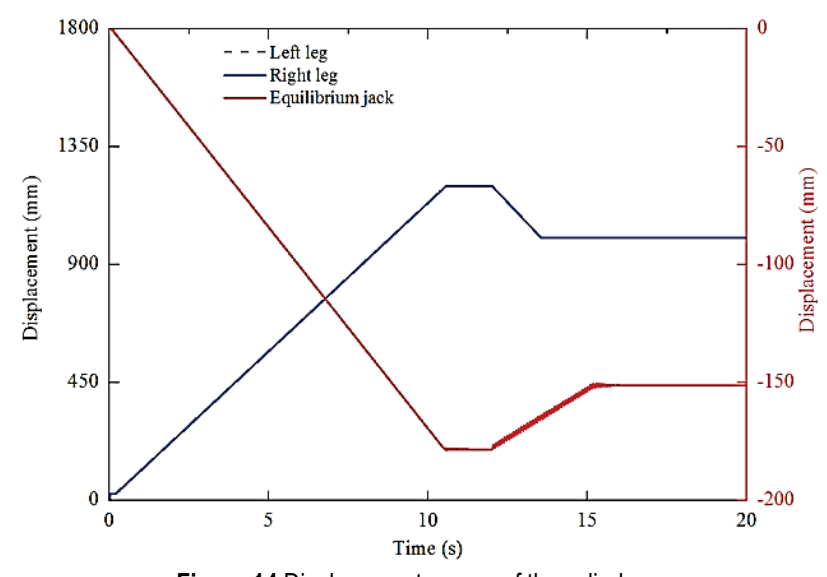

Figure 14 Displacement curves of the cylinders.

Figs. 14 and 15 show the time-dependent displacement charts for the legs and equilibrium jack, whereas Figs. 16 and 17 show the time-dependent flow rate and pressure charts for the legs and equilibrium jack. At $0 \mathrm{~s}$, the support starts adjusting its pose according to user's input data. Due to the initial length of the leg and equilibrium jack is quite 
different from the target value, the PID controller outputs the maximum value and makes the solenoid directional valves open. The leg and equilibrium jack (rodless cavity) begin to bear the inertia force of the canopy. Because the diameter of the leg is much larger than the equilibrium jack, the pressure fluctuation of the equilibrium jack is larger. The leg and the equilibrium jack reach the target length at $10.6 \mathrm{~s}$ (the motion accuracy is less than $1.5 \mathrm{~mm}$ ). Then, the output of the PID controller becomes 0 , and the lengths of the leg and equilibrium jack remain unchanged. Due to the inertia effect, the canopy will produce a tendency to rotate around the leg, thus cause the displacement and pressure fluctuation of the equilibrium jack (This is why the Accurracy tolerance module is set). At this time, the support should switch to the pressurization system to increase the initial setting pressure. At $12 \mathrm{~s}$, the user changes the input pose data of the support. The support enters the pose adjustment process again. At this time, the rod cavity of the equilibrium jack is subjected to the outerload. The pressure and displacement of the equilibrium jack fluctuate more greatly. The support system reaches a stable state at about $15 \mathrm{~s}$. Since the pressure, flow rate, and displacement of the legs (the left leg and the right leg) are strictly symmetrical, the model built in this study is reliable. The PID controller can accurately adjust the lengths of the leg and equilibrium jack to drive the support to reach the target pose.

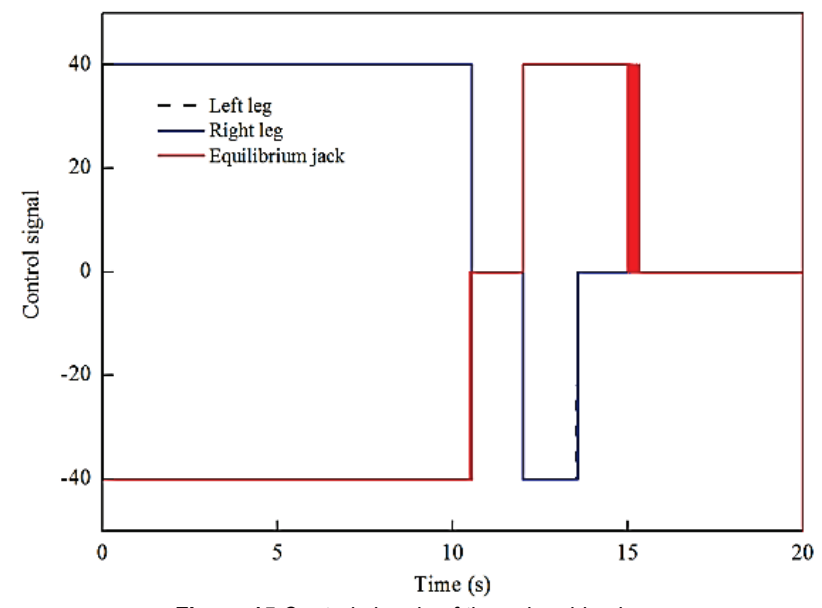

Figure 15 Control signals of the solenoid valves

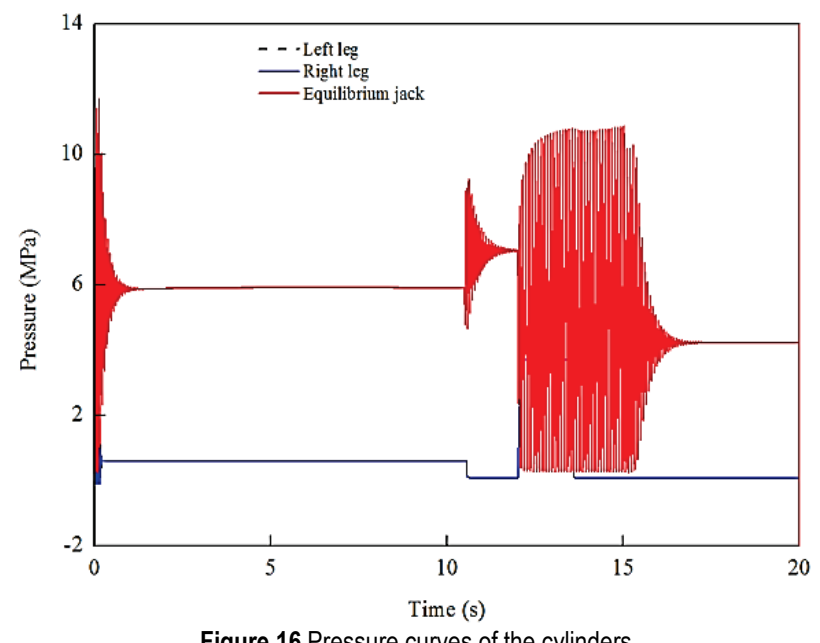

Figure 16 Pressure curves of the cylinders

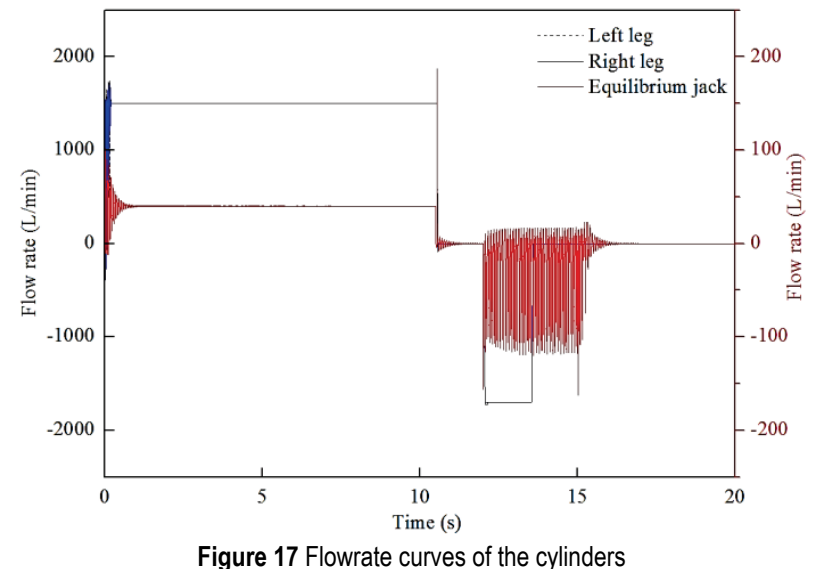

\section{CONCLUSIONS}

The performance of a powered support depends not only on its pressure but also on the pose and the pose adjusting speed. In order to realize the pose monitoring and control of a support and to improve its supporting performance, it is necessary to develop mathematical and numerical models which combine different physical aspects of mechanical-electrical-hydraulic system operations. The paper presented this process based on the example of a 2-leg shield-type support. The connection between the mechanical, electrical and hydraulic systems was achieved by establishing the data interface.

The TLBO algorithm was used to rapidly and accurately solve the nonlinear pose equations of support (iteration time less than $1 \mathrm{~s}$ ). After reading the target pose data supplied by the user, the developed pose controller automatically calculated the required lengths of the leg and the equilibrium jack. Then, the controller adjusted the support to the target pose accordingly (cumulative error less than $1.5 \mathrm{~mm})$.

The simplified model of the pose adjusting process did not yield very accurate results. However, the assumption shortened the simulation time significantly. This advantage offers the possibility for further studies on developing flexible support model for predicting support system dynamic responses under impact loading. This study is useful in overcoming the problems of pose monitoring and controlling of hydraulic support in engineering, and provides theoretical basis and technical guidance for the automation and unmanned control of underground mining. However, the pose calculation accuracy of the hydraulic support is also affected by the assembly accuracy of the pin shaft, thus, the assembly accuracy should also be considered to obtain more accurate results.

\section{Acknowledgements}

This work was supported by the the Key Research and Development project of China (Grant No. 2017YFC0603000); the Natural Science Foundation of China (No. 51375282); the Natural Science Foundation of Shandong Province, China (No. ZR2014EEM021).

\section{REFERENCES}

[1] Mangal, A. \& Paul, P. S. (2016). Rock mechanical investigation of strata loading characteristics to assess caving 
and requirement of support resistance in a mechanized powered support longwall face. International Journal of Mining Science and Technology, 26(6), 1081-1087. https://doi.org/10.1016/j.ijmst.2016.09.017

[2] Prusek, S., Płonka, M., \& Walentek, A. (2016). Applying the ground reaction curve concept to the assessment of shield support performance in longwall faces. Arabian Journal of Geosciences, 9(3), 1-15. https://doi.org/10.1007/s12517-015-2171-2

[3] Peng S. S. (2006). Longwall mining, $2^{\text {th }}$ edition, Morgantown, WV: West Virginia University Books.

[4] Yetkin, M. E., Simsir, F., Ozfirat M. K., Ozfirat P. M., \& Yenice, H. (2016). A fuzzy approach to selecting roof supports in longwall mining. South African journal of industrial engineering, 27(1), 162-177. https://doi.org/10.7166/27-1-1366

[5] Singh, G. S. P. \& Singh, U. K. (2009). A numerical modeling approach for assessment of progressive caving of strata and performance of hydraulic powered support in longwall workings. Computers and Geotechnic, 36(7), 1142-1156. https://doi.org/10.1016/j.compgeo.2009.05.001

[6] Singh, G. S. P. \& Singh, U. K. (2010). Prediction of caving behavior of strata and optimum rating of hydraulic powered support for longwall workings. International Journal of Rock Mechanics and Mining Sciences, 47(1), 1-16. https://doi.org/10.1016/j.jijmms.2009.09.001

[7] Holub, K., Rusajova, J., \& Holecko, J. (2011). Particle velocity generated by rockburst during exploitation of the longwall and its impact on the workings. International Journal of Rock Mechanics and Mining Sciences, 48(6), 942949. https://doi.org/10.1016/j.jirmms.2011.05.004

[8] Verma, A. K. (2013). Numerical Analysis of an Interaction between Hydraulic-Powered Support and Surrounding Rock Strata. International Journal of Geomechanics, 13(2),181192. https://doi.org/10.1061/(ASCE)GM.1943-5622.0000190

[9] Gao, F., Stead, D., \& Coggan, J. (2014). Evaluation of coal longwall caving characteristics using an innovative UDEC Trigon approach. Computers and Geotechnics, 55, 448-460. https://doi.org/10.1016/j.compgeo.2013.09.020

[10] Shabanimashcool, M., Jing, L., \& Li, C. C. (2014). Discontinuous modeling if stratum cave-in in a longwall coal mine in the Arctic area. Geotechnical and Geological Engineering, 32(5), 1239-1252. https://doi.org/10.1007/s10706-014-9795-y

[11] Trueman, R., Lyman, G., \& Cocker, A. (2009). Longwall roof control through a fundamental understanding of shieldstrata interaction. International Journal of Rock Mechanics and Mining Sciences, 46(2), 371-380. https://doi.org/10.1016/j.jijmms.2008.07.003

[12] Cheng, J. Y., Wang, Z. J., Peng, S. S., Liu, S. F., \& Ji, Y. L. (2015). What can the changes in shield resistance tell us during the period of shearer's cutting and neighboring shields' advance? International Journal of Mining Science and Technology, 25(3), 361-367. https://doi.org/10.1016/j.ijmst.2015.03.006

[13] Trueman, R., Thomas, R., \& Hoyer, D. (2012) Understanding the causes of roof control problems on a longwall face from shield monitoring data - a case study. $11^{\text {th }}$ Underground Coal Operators Conference, 40-47.

[14] Li, H. M., Jiang, D. J., Peng, S. S., \& Feng, J. F. (2015). Analysis on loading feathers and suitability of hydraulic powered caving supports. Coal science and Technology, 43(6), 23-29. https://doi.org/10.13199/j.cnki.cst.2015.06.005

[15] Meng, Z. S., Zeng, Q. L., Gao, K. D., Kong, S., Liu, P., \& Wan, L. R. (2018). Failure analysis of super-large mining height powered support. Engineering Failure Analysis, 92, 378-391. https://doi.org/10.1016/j.engfailanal.2018.04.011

[16] Mężyk, A., Klein, W., Fice, M., Pawlak, M., \& Basiura, K. (2016). Mechatronic model of continuous miner cutting drum driveline. Mechatronics, 37(SI), 12-20. https://doi.org/10.1016/j.mechatronics.2015.11.004

[17] Sudharsan, J. \& Karunamoorthy, L. (2016). Path Planning and co-simulation control of 8 DOF anthropomorphic robotic arm. International Journal of Simulation Modelling, 15(2), 302-312. https://doi.org/10.2507/ijsimm15(2)9.339

[18] Roccatello, A., Mancò, S., \& Nervegna, N. (2007). Modelling a Variable Displacement Axial Piston Pump in a multibody Simulation Environment. Journal of Dynamic Systems Measurement and Control, 129(4), 819-829. https://doi.org/10.1115/1.2745851

[19] Kangab, S. \& Minb, Y. (2016). Dynamic simulation of a fuel cell hybrid vehicle during the federal test procedure-75 driving cycle. Applied Energy, 161(1), 181-196. https://doi.org/10.1016/j.apenergy.2015.09.093

[20] Dai, Y., Zhu, Y. \& Chen, L. S. (2016). A MechanicalHydraulic Virtual Prototype Co-Simulation Model for a Seabed Remotely Operated Vehicle. International Journal of Simulation Modelling, 15(3): 532-541. https://doi.org/10.2507/IJSIMM15(3)C011

[21] Zeng, Q. L., Gao, K. D., Zhang, H. Z., Jiang, S. B., \& Jiang, K. (2017). Vibration analysis of shearer cutting system using mechanical hydraulic collaboration simulation. Proceedings of the Institution of Mechanical Engineers, Part K: Journal of Multi-body Dynamics, 231(4), 708-725. https://doi.org/10.1177/1464419317705986

[22] Carretero, J. (2000). Kinematic analysis and optimization of a new three degree-of-freedom spatial parallel manipulator. Journal of Mechanical Design, 122(1), 17-24. https://doi.org/10.1115/1.533542

[23] Oblak, M., Harl, B., \& Butinar B. (2000). Optimal design of hydraulic support. Structural and Multidisciplinary Optimization. 20(1), 76-82. https://doi.org/10.1007/s001580050138

[24] Prebil, I., Krašna, S., \& Ciglarič, I. Synthesis of four-bar mechanism in a hydraulic support using a global optimization algorithm. Structural and Multidisciplinary Optimization, 24(3), 246-251 https://doi.org/10.1007/s00158-002-0234-y

[25] Oblak, M., Ciglarič, I., \& Harl, B. (2015). The optimal synthesis of hydraulic support. Zamm-Journal of Applied Mathematics and Mechanics / Zeitschrift Für Angewandte Mathematik Und Mechanik, 78(S3),1027-1028. https://doi.org/10.1002/zamm.19980781582

[26] Al-Qahtani, H. M., Mohammed, A. A., \& Sunar, M. (2016). Dynamics and Control of a Robotic Arm Having Four Links. Arabian Journal for Science and Engineering, 42(5), 1-12. https://doi.org/10.1007/s13369-016-2324-y

[27] Lin, W. Y. \& Hsiao, K. M. (2017). Cuckoo search and teaching-learning-based optimization algorithms for optimum synthesis of path-generating four-bar mechanisms. Journal of the Chinese institute of engineers, 40(1), 66-74. https://doi.org/10.1080/02533839.2016.1273142

[28] Ebrahimi, S. \& Payvandy, P. (2015). Efficient constrained synthesis of path generating four-bar mechanisms based on the heuristic optimization algorithms. Mechanism and Machine Theory, 85, 189-204. https://doi.org/10.1016/j.mechmachtheory.2014.11.021

[29] Zhang, Q., Ji, L., Zhou, D., \& Wei, X. P. (2015). Nonholonomic motion planning for minimizing base disturbances of space manipulators based on multi-swarm PSO. Robotica, 35(4), 1-15. https://doi.org/10.1017/S0263574715000855

[30] Rao, R. V. \& Waghmare, G. (2015). Design optimization of robot grippers using teaching-learning-based optimization algorithm. Advanced robotics, 29(6), 431-447. https://doi.org/10.1080/01691864.2014.986524

[31] Cruz, R. S. N. \& Zannatha, J. M. I. (2016). Efficient mechanical design and limit cycle stability for a humanoid robot: An application of genetic algorithms. Neurocomputing, 233(SI), 72-80. 
https://doi.org/10.1016/j.neucom.2016.08.113

[32] Atacak, I. \& Küçük, B. (2017). PSO-based PID controller design for an energy conversion system using compressed air. Tehnicki Vjesnik, 24(3): 671-679. https://doi.org/10.17559/TV-20150310170741

[33] Cho, H. J., Ahmed, F., Kim, T. Y., Kim, B. S., \& Yeo, Y. K. A comparative study of teaching-learning-self-study algorithms on benchmark function optimization. Korean journal of chemical engineering, 34(3), 628-641. https://doi.org/10.1007/s11814-016-0317-x

[34] Guha, D., Roy, P. K., \& Banerjee, S. (2017). Study of differential search algorithm based automatic generation control of an interconnected thermal-thermal system with governor dead-band. Applied Soft Computing, 52, 160-175. https://doi.org/10.1016/j.asoc.2016.12.012

[35] Jiang, S. B., Zhang, X., Gao, K. D., Gao, J., Wang, Q. Y., \&Hidenori, K. (2017). Multi-body dynamics and vibration analysis of chain assembly in armoured face conveyor. International Journal of Simulation Modelling, 16(3), 458470. https://doi.org/10.2507/IJSIMM16(3)8.391

\section{Contact information}

\section{Zhaosheng MENG}

Department of Mechatronics and Engineering,

Shandong University of Science and Technology,

Qingdao, China-266590

E-mail: skdmzs@sdust.edu.cn

\section{Qingliang ZENG}

(Corresponding author)

Department of Mechatronics and Engineering,

Shandong University of Science and Technology,

Qingdao, China-266590

E-mail: qlzeng@sdust.edu.cn

\section{Lirong WAN}

Department of Mechatronics and Engineering,

Shandong University of Science and Technology,

Qingdao, China-266590

E-mail: wanlr666@163.com

\section{Peng LIU}

Department of Mechatronics and Engineering,

Shandong University of Science and Technology,

Qingdao, China-266590

E-mail: pengl0328@163.com

\section{Nomenclature}

$h_{1} \quad$ Distance between A and the base $(500 \mathrm{~mm})$

$h_{2}$ Distance between D and the base $(1300 \mathrm{~mm})$

$h_{3}$ Distance between J and the base $(550 \mathrm{~mm})$

$h_{4}$ Distance between E and the canopy $(380 \mathrm{~mm})$

$h_{5}$ Distance between F and the canopy $(850 \mathrm{~mm})$

$h_{6}$ Distance between I and the canopy $(600 \mathrm{~mm})$

$H^{\prime} \quad$ Operating height of the support

$l_{1} \quad$ Length of line $\mathrm{AB}(3350 \mathrm{~mm})$

$l_{2} \quad$ Length of line $\mathrm{AD}(1400 \mathrm{~mm})$

$l_{3} \quad$ Length of line $\mathrm{CD}(3400 \mathrm{~mm})$

$l_{4} \quad$ Length of line $\mathrm{BC}(650 \mathrm{~mm})$

$l_{5} \quad$ Length of line BE $(4500 \mathrm{~mm})$

$l_{6} \quad$ Length of line EG $(1680 \mathrm{~mm})$

$l_{7} \quad$ Length of line EF $(630 \mathrm{~mm})$

$l_{8} \quad$ Horizontal distance between $\mathrm{E}$ and I $(1350 \mathrm{~mm})$

l9 Horizontal distance between $\mathrm{A}$ and $\mathrm{J}(2250 \mathrm{~mm})$

$l_{z} \quad$ Length of the leg

$l_{q} \quad$ length of the equilibrium jack

$\varepsilon \quad$ Angle between the canopy and the ground

$\theta_{0} \quad$ Angle between line $\mathrm{AB}$ and the ground

$\theta_{1} \quad$ Angle between line $\mathrm{AB}$ and line $\mathrm{AD}$

$\theta_{2} \quad$ Angle between line $\mathrm{AD}$ and the ground

$\theta_{3} \quad$ Angle between line $\mathrm{AB}$ and line $\mathrm{BD}$

$\theta_{4} \quad$ Angle between line $\mathrm{BD}$ and line $\mathrm{BC}$

$\theta_{5} \quad$ Angle between line $\mathrm{BC}$ and line $\mathrm{BE}$

$\theta_{6} \quad$ Angle between line $\mathrm{BE}$ and the ground

$\theta_{7} \quad$ Angle between line BE and horizontal canopy

$\theta_{8} \quad$ Angle between line EG and line EB

$\theta_{9} \quad$ Angle between line EF and line EG

$\theta_{10} \quad$ Angle between line EF and the canopy

$\theta_{11} \quad$ Angle between the leg and the ground 